\title{
A Comparison of Electronic Patient-Portal Use Among Patients with Resident and Attending Primary Care Providers
}

\author{
Brian Chan, MD MPH', ${ }^{1,2}$ Courtney Lyles, $P h D^{2,3}$, Celia Kaplan, DrPH 4 , Rosemary Lam, BA ${ }^{4}$, and \\ Leah Karliner, MD MAS4
}

'Division of General Internal Medicine and Geriatrics, Oregon Health \& Science University, Portland, OR, USA; ${ }^{2}$ Division of General Internal Medicine, Zuckerberg San Francisco General Hospital, University of California, San Francisco, CA, USA; ${ }^{3}$ UCSF Center for Vulnerable Populations, Zuckerberg San Francisco General Hospital, San Francisco, CA, USA; ${ }^{2}$ Division of General Internal Medicine, Multiethnic Health Equity Research Center,

University of California, San Francisco, CA, USA.

\begin{abstract}
BACKGROUND: Electronic patient-portals offer the potential to enhance patient-physician communication and health outcomes but differential use may create or worsen disparities. While prior studies identified patient characteristics associated with patient-portal use, the role of physician factors is less known. We investigated differences in overall and patterns of portal use for patients with resident and attending primary care providers (PCPs).
\end{abstract}

METHODS: Cross-sectional study of all established patients with a resident or attending PCP seen at an academic internal medicine practice (two sites) between May 1, 2014, and April 30, 2015. We defined patientportal use as having accessed any "active" (secure messaging, medication refill request), or "passive" (viewing labs, after visit summaries, or appointments) patientportal function more than once over the study period. We used generalized linear models clustered on PCP to examine the odds of patient-portal use by PCP type, adjusted for patient age, gender, preferred language, race/ethnicity, insurance, and visits. Among patient-portal users, we examined the association of PCP type with "active use" utilizing the same method.

RESULTS: The mean patient age $(n=17,699)$ was 54.2 (SD 17.5), with 47.2\% White, 23.6\% Asian, 8.8\% Black, $8.4 \%$ Latino, and $12 \%$ other/unknown. The majority $(61.8 \%)$ had private insurance, and attending PCPs (76.9\%). Although 72.3\% enrolled in the patient-portal, only $53.4 \%$ were portal users; $40.0 \%$ were active users. There were 47 attending and 62 resident physicians. Patients with resident PCPs had lower odds of using the portal compared to those with attending PCPs $(\mathrm{OR}=0.54$, 95\% CI 0.50-0.59). Similarly, among portal users, residents' patients had lower odds of being active users of the portal $(\mathrm{OR}=0.76,95 \%$ CI 0.68-0.87).

CONCLUSION: Given the lower patient-portal use among residents' patients, residency programs should develop curricula to bolster trainee competence in using the patient-portal for communication and to enhance the patient-physician relationship. Future research should explore additional physician factors that impact portal use.

Received November 14, 2017

Revised June 28, 2018

Accepted July 24, 2018

Published online September 5, 2018
KEY WORDS: patient-portal; physician-patient communication; disparities; resident training.

J Gen Intern Med 33(12):2085-91

DOI: $10.1007 / \mathrm{s} 11606-018-4637-x$

(c) Society of General Internal Medicine 2018

\section{INTRODUCTION}

Electronic patient-portals (EPP) offer the potential for increased patient-physician communication and improved clinical care beyond the office visit. ${ }^{1}$ Patient-portals empower patients to access their electronic health record and interface with their care teams. Adoption of patient-portals is integrated into federal "meaningful use" metrics, and is necessary for receipt of financial incentives associated with implementing electronic health records (EHR). ${ }^{2}$ As a result, studies estimate adoption rates have increased to $52 \%$, though when stratified by uncontrolled and controlled studies, rates varied from 23 to $70 \%$, respectively. ${ }^{3}$

Use of patient-portals may hold promise for improved patient outcomes, utilization, and patient experience, although there is conflicting evidence. ${ }^{4-6}$ A longitudinal study of 6300 diabetes patients in a large health system found an association between higher frequency of secure messaging during the previous calendar quarter, good glycemic control, and higher rates of testing adherence. ${ }^{7}$ In a large cohort of diabetes patients, use of an online refill function for statins improved medication adherence. ${ }^{8}$ Patient-portals positively impact population health efforts - an RCT of patient-portal linked health maintenance reminders in a large multi-site practice led to significant increases in mammography and influenza vaccination rates. ${ }^{9}$ There is less evidence on the impact of patientportals on health utilization and efficiency; an examination of recently discharged patients and new patient-portal use showed that active users of the portal (defined by use of messaging functions) were $66 \%$ times more likely to experience 30-day readmission compared to non-users. ${ }^{10}$

As health systems increasingly rely on electronic patientportals, there is a need to understand the factors that promote patient use of these portals so as to not exacerbate existing health disparities. Prior studies show that patients who are 
White, younger, of higher health literacy, or of higher socioeconomic status have higher rates of patient-portal use, ${ }^{5,11,12}$ and that non-White and older patients express difficulty accessing health information and physicians as a result. ${ }^{13}$ There is evidence of a "digital divide" that accounts for these differences. ${ }^{14}$ But few studies have examined the influence of physician factors on patient adoption and use of patient-portals, though there is early evidence that physician encouragement and patient-physician trust may have an impact on patient-level portal use. ${ }^{15}$ Conversely, physician concerns regarding patient-portal use, including fear of increased workload, confusing patients, and differential treatment of users and non-users, may contribute to lack of portal uptake. ${ }^{16,17}$

No studies to date have examined the influence of physician type on patient-portal use. Due to the nature of their training, resident physicians have less opportunity for building longitudinal relationships with patients, and may lack expertise in effective use of patient-portals, which in turn could lead to less patient adoption of patient-portals. ${ }^{18}$ In this study of patients in an integrated faculty-resident practice, we investigate differences in overall portal use and patterns of portal use for patients with resident and attending primary care providers (PCPs).

\section{METHODS}

\section{Setting}

We performed a cross-sectional analysis of patient-portal use linked to EHR data of the internal medicine primary care practice at University of California, San Francisco (UCSF), an academic medical center. UCSF general internal medicine (GIM) provides primary care to a diverse population of approximately 24,000 patients in two main practice sites that are located in close geographic proximity and under the same practice umbrella. The patient-portal MyChart (EpicCare, Verona, WI) was introduced in 2011 featuring secure messaging with practice providers, and ability to request medication refills and to view appointments, test results, after-visit summaries (AVS), medical problem lists, allergies, and immunizations.

\section{Patients}

The study sample included established GIM patients $\geq 18$ years old with a resident or attending PCP during the study period of May 2014 through April 2015. We chose this time frame as it followed an institution-wide effort to enroll patients in the patient-portal that included patient information and on-site staff to assist patients; this effort did not differ for the two GIM clinic sites. We defined established patients as those seen in the practice at least once in the 12 months prior to the study period. All residents $(N=62)$ were at one clinic site alongside 36 of 47 attending physicians - the remainder were at the second practice site. We excluded patients who did not have an assigned PCP during the study period. Due to the small number of NPs in the practice, we also excluded patients with an NP PCP. The UCSF Institutional Review Board approved the research procedures.

\section{Outcomes}

The primary outcomes of interest were as follows: (1) use of the patient-portal, and among users (2) active use of the patient-portal. We defined use of patient-portal as having accessed any of the functions of the patient-portal more than one time during the study period: (a) viewed lab results or diagnostic imaging reports; (b) viewed an AVS; (c) viewed upcoming appointments; (d) used the medication refill request function; (e) used the free-text secure messaging function to message with a provider. Similar to a prior study, we defined active use as those who accessed the medication refill request function and/or the free-text secure messaging function more than one time during the study period because these functions require more active patient involement. ${ }^{10}$ We defined all other functions listed above as passive use, as they are limited to viewing information. Enrollment was defined as the presence of a documented date that the patient established a patientportal account.

\section{Independent Variable and Covariates}

The primary predictor of interest was PCP type (resident MD vs attending MD) defined as the PCP field in the EHR, which is updated at least annually by the practice. We obtained patientlevel covariates from the EHR including the following: (1) age (<50, 51-64, 65-74, 75+ years); (2) sex; (3) race/ethnicity (nonLatino White, non-Latino Black, Latino/Hispanic, Asian/Asian Pacific Islander (API), and other); (4) preferred language for healthcare (English/non-English); (5) insurance (commercial, Medicaid, Medicare (including Medicare advantage), Medicaid and Medicare ("dual eligible"), other); (6) practice location, (7) zip code (San Francisco vs outside San Francisco); and (8) average number of visits per year over a 2 -year period (12 months prior to and 12 months during the study period).

\section{Analyses}

We examined the unadjusted associations between physician type and patient-portal use, and use pattern with chi-square, $t$ tests, and Wilcoxon rank-sum tests. We then modeled the association of physician type with use of the patient-portal accounting for PCP clustering using generalized linear models for binomial outcomes, adjusting for patient age, gender, race/ethnicity, preferred language, insurance status, number of visits per year, and zip code. We further modeled the association of physician type with active use (vs passive use), adjusting for the same covariates.

\section{Secondary Analyses-Including Physician Covariates}

In order to further investigate the impact of physician characteristics on patient use and active use of the portal, 
we conducted additional analyses incorporating physician characteristics. We included rank (resident, fellow, assistant professor, associate professor, full professor), physician gender, and physician-patient gender concordance.

\section{RESULTS}

There were 19,898 established patients in the sample. Of these, $1526(7.7 \%)$ had a NP PCP and 673 (3.4\%) did not have an identified PCP during the study period and were excluded from the analysis. The mean age of the remaining patients $(17,699)$ was 53.4 years, with $47.2 \%$ nonLatino White, 23.6\% Asian, 8.8\% Black/non-Latino, 8.4\% Latino, and $12.0 \%$ other/unknown. Over half the patients were female $(52.2 \%)$, and $84.9 \%$ indicated English as their preferred language. The majority $(61.8 \%)$ of patients had commercial insurance, $10.1 \%$ had Medicaid, and $24.7 \%$ had Medicare. Patients averaged 3.3 practice visits per year. The majority of patients had an attending PCP, while $23.2 \%$ had a resident PCP. There were differences in patient age, preferred language, insurance status, mean number of visits, and zip code by physician type (Table 1).

\section{Physician Characteristics}

There were a total of 109 physicians: 47 (43.1\%) were attendings (23 full professor, 9 associate, 11 assistant, 4 fellow), and $62(56.9 \%)$ were residents. The majority were female (58.7\%) and there was gender concordance for $66 \%$ of patient-PCP pairs.

\section{Use Versus Non-Use of the Patient-Portal}

Among the patients in the sample, 53.4\% were patientportal users (Fig. 1). Of note, $19.0 \%$ of patients enrolled in the portal but never used it. In unadjusted comparisons, $58.2 \%$ of patients with attending PCPs were users of patient-portals, compared to $38.7 \%$ of patients with resident PCPs $(p<.01)$ (Table 2). There were positive associations between portal use and being ages 50-74, White, and privately insured, English-speaking, and living outside San Francisco.

\section{Active Versus Passive Use of the Patient-Portal}

Among the 9443 patient-portal users, $74.5 \%$ were active users. In unadjusted comparisons, $75.9 \%$ of patient-portal users who had attending PCPs were active users, compared to $68.1 \%$ of patients who had resident PCPs $(p<.01)$. There were positive associations between active portal use and being middle-aged or older and White, English-speaking, having Medicare or being dual-eligible (Medicaid and Medicare), living outside of San Francisco, and having more practice visits per year (Table 2).
Table 1 Characteristics of an Academic General Internal Medicine Panel Including Patients with a Resident or Attending PCP and At Least One Practice Visit from May 1, 2014 to April 30, 2015

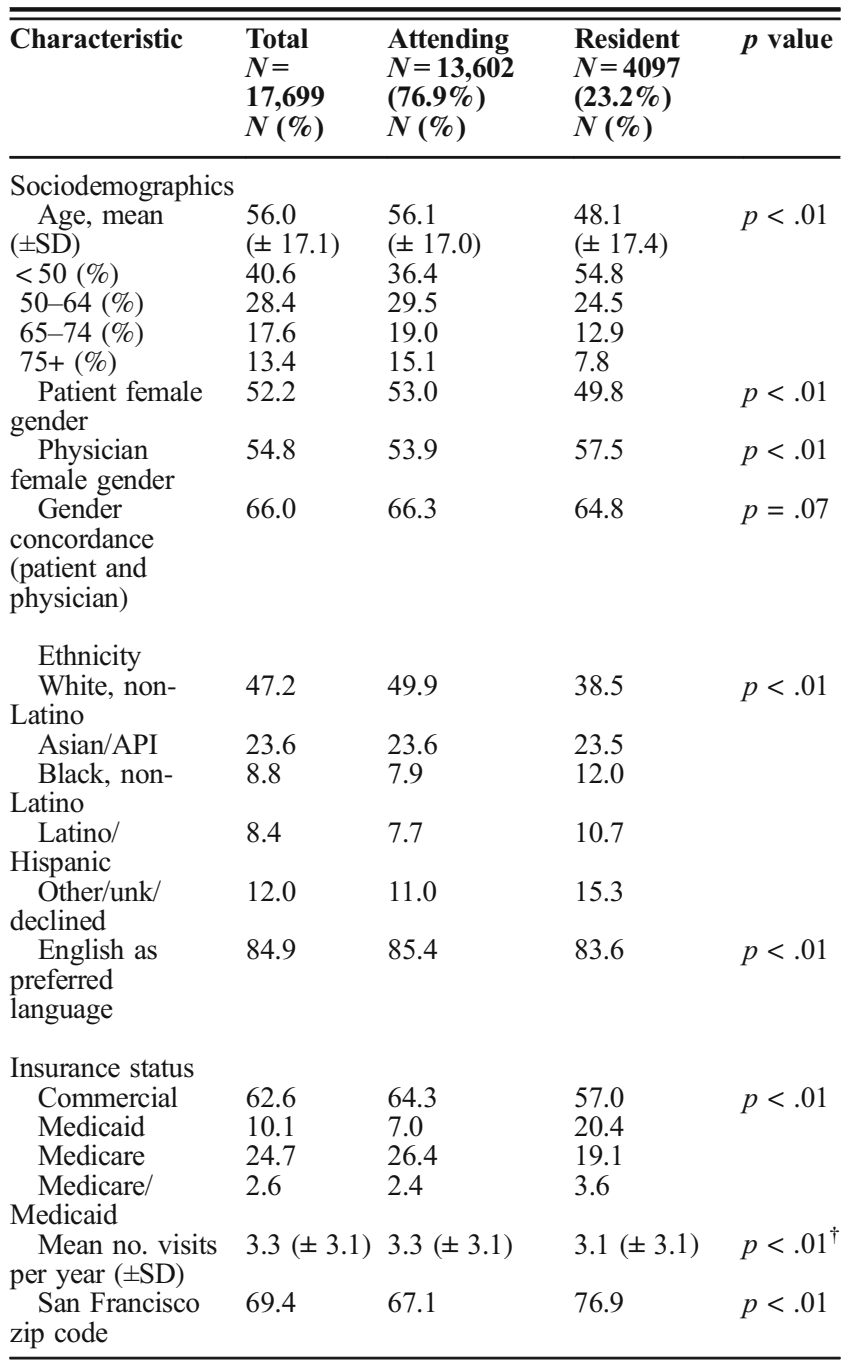

All presented percents are column percents

$\uparrow K$-W statistic used for comparison

\section{Multivariable Analyses}

In adjusted models (Table 3), patients with a resident PCP had half the odds of being a patient-portal user compared to patients with an attending PCP (OR $=0.55,95 \%$ CI $0.51-$ $0.60)$. Similarly among users of the patient-portal, patients with a resident PCP had lower adjusted odds of active portal use compared to patients with an attending $\mathrm{PCP}(\mathrm{OR}=0.78$, 95\% CI 0.68-0.88).

Patients aged 65-74 (compared to patients aged 50-64) and women had higher odds of both use and active use of portals (Table 3). Additionally, each additional clinic visit led to increased odds of being a user and active user of the portal. On the other hand, patients ages $<50$, race/ethnic minorities, and non-English speakers all had lower odds both of being a portal user and of being an active user. While those with public insurance had lower odds of being a portal user, once they were a user, there was no difference in odds of being an active user. In contrast, those living outside San Francisco had higher 


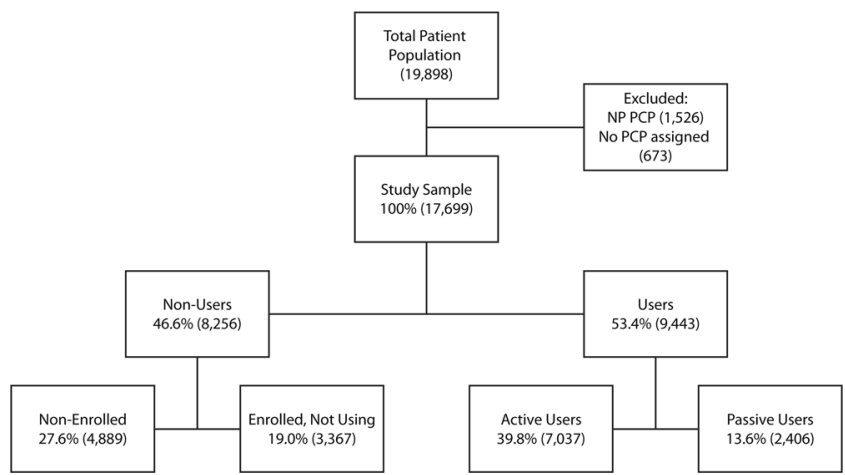

Fig. 1 Description of the study sample and patient portal use patterns. Enrolled - patients who had documented date of patientportal account creation. Non-Enrolled-patients without date of patient-portal account creation. Users-patients who accessed any patient-portal function more than once during the study period, including the following: (a) viewed lab results or diagnostic imaging reports; (b) viewed an after visit summary; (c) viewed upcoming appointments; (d) used the medication refill request function; (e) used the free-text secure messaging function to message with a provider. Active-Users - users who accessed the medication refill request function and/or the free-text secure messaging function. Passive-User-users who only accessed patient-portal function to view information.

odds of being a portal user, but once they were a user, there was no difference in odds of being an active user.

In secondary analyses including detailed physician characteristics, patients of attending physicians at all ranks had higher portal use than patients of resident physicians.
However, there was a gradient of increasing patient use with increasing attending rank from assistant to associate to full professor. Neither physician gender nor physician-patient gender concordance was significant in adjusted models (Table 4).

\section{DISCUSSION}

In this study of patients seen in an integrated faculty-resident GIM practice, we found a disparity in use and pattern of use of the electronic patient-portal for patients with a resident physician PCP compared to those with an attending physician PCP. We also found a gradient of use, with higher use among patients with more experienced attending physicians. To our knowledge, this is the first study to examine differences in patient-portal use by physician rank. We also confirmed existing race/ethnic, SES, and age disparities in portal use, and found that patients with more practice visits had higher rates of patient-portal use.

Patients perceive patient-portals as an efficient tool for health communication ${ }^{4,19}$ but disparities in use by race/ethnicity, SES, and age continue to exist. ${ }^{20}$ Reasons for this focus on the role of the "digital divide," access or unfamiliarity with health information technology, ${ }^{21}$ and patient concerns that portals may erode personal relationships with physicians. ${ }^{22}$ However, our findings suggest physician factors may also play a role in

Table 2 Characteristics of Patients with Patient-Portal Use vs Non-Use and Passive and Active Portal Use at an Academic General Internal Medicine Practice (May 1, 2014-April 30, 2015)

\begin{tabular}{|c|c|c|c|c|c|c|}
\hline \multirow[t]{2}{*}{ Characteristic } & \multicolumn{3}{|c|}{$\begin{array}{l}\text { All included patients }(N=17,699) \\
N(\%)\end{array}$} & \multicolumn{3}{|c|}{$\begin{array}{l}\text { Patient-portal users }(N=9443) \\
N(\%)\end{array}$} \\
\hline & $\begin{array}{l}\text { Non-use } \\
N=8256\end{array}$ & $\begin{array}{l}\text { Use } \\
N=9443\end{array}$ & $p$ value & Passive use $N=2406$ & Active use $N=7037$ & $p$ value \\
\hline \multicolumn{7}{|l|}{ Physician type } \\
\hline Attending & 42.3 & 57.7 & $p<.01$ & 24.2 & 75.8 & $p<.01$ \\
\hline Resident & 61.2 & 38.8 & & 31.9 & 68.1 & \\
\hline \multicolumn{7}{|l|}{ Sociodemographics } \\
\hline Age, mean $( \pm \mathrm{SD})$ & $53.9( \pm 19.0)$ & $54.4( \pm 16.1)$ & $p=.18$ & $51.5( \pm 16.3)$ & $55.3( \pm 16.1)$ & $p<.01$ \\
\hline$<50(\%)$ & 49.5 & 50.5 & $p<.01$ & 31.2 & 68.8 & $p<.01$ \\
\hline $50-64(\%)$ & 40.4 & 59.6 & & 23.6 & 76.4 & \\
\hline 65-74 (\%) & 40.0 & 60.0 & & 18.4 & 81.6 & \\
\hline $75+(\%)$ & 59.8 & 40.2 & & 23.3 & 76.7 & \\
\hline \multicolumn{7}{|l|}{ Patient gender } \\
\hline Female & 46.3 & 53.7 & $p=.37$ & 25.0 & 75.0 & $p=.25$ \\
\hline Male & 47.7 & 53.0 & & 26.0 & 74.0 & \\
\hline \multicolumn{7}{|l|}{ Race/ethnicity } \\
\hline White, non-Latino & 37.1 & 62.9 & $p<.01$ & 22.5 & 77.5 & $p<.01$ \\
\hline Asian/API & 50.5 & 49.5 & & 31.9 & 68.1 & \\
\hline Black, non-Latino & 66.2 & 33.8 & & 24.6 & 75.4 & \\
\hline Latino/Hispanic & 60.1 & 39.9 & & 26.7 & 73.3 & \\
\hline Other/unk/declined & 52.9 & 47.1 & & 27.5 & 72.5 & \\
\hline \multicolumn{7}{|l|}{ Primary language } \\
\hline English & 43.1 & 56.9 & $p<.01$ & 24.4 & 75.6 & $p<.01$ \\
\hline Non-English & 67.1 & 32.9 & & 36.0 & 64.0 & \\
\hline \multicolumn{7}{|l|}{ Insurance status } \\
\hline Commercial & 39.4 & $60.6 \%$ & $p<.01$ & 26.5 & 73.5 & $p<.01$ \\
\hline Medicaid & 67.5 & $32.5 \%$ & & 29.9 & 70.0 & \\
\hline Medicare & 53.5 & $46.5 \%$ & & 21.1 & 78.9 & \\
\hline Medicare/Medicaid & 68.4 & $31.6 \%$ & & 23.1 & 76.9 & \\
\hline Mean no. visits per year $( \pm S D)$ & $3.2( \pm 3.5)$ & $3.3( \pm 2.8)$ & $p<.01^{\dagger}$ & $2.7( \pm 2.3)$ & $3.5( \pm 2.9)$ & $p<.01^{\dagger}$ \\
\hline San Francisco zip code & 49.6 & 50.4 & $p<.01$ & 26.5 & 73.5 & $p=.001$ \\
\hline
\end{tabular}

*All presented percents are row percents

†Wilcoxon rank sum test used for comparison 
Table 3 Multivariate Odds of Any Use and Active Use of the Patient-Portal at an Academic General Internal Medicine Practice Clustered by Physician (May 1, 2014-April 30, 2015)

\begin{tabular}{|c|c|c|}
\hline & \multirow{2}{*}{$\begin{array}{l}\begin{array}{l}\text { Odds of use } \\
N=17,699\end{array} \\
\begin{array}{l}\text { Adjusted OR } \\
(95 \% \text { CI })\end{array}\end{array}$} & \multirow{2}{*}{$\begin{array}{l}\text { Odds of active use } \\
N=9443 \\
\begin{array}{l}\text { Adjusted OR } \\
(95 \% \text { CI })\end{array}\end{array}$} \\
\hline & & \\
\hline \multicolumn{3}{|l|}{ Physician type } \\
\hline Attending (Ref) & 1.0 & 1.0 \\
\hline Resident & $0.55(0.51,0.59)$ & $0.74(0.65,0.84)$ \\
\hline \multicolumn{3}{|l|}{ Age } \\
\hline$<50$ & $0.75(0.69,0.81)$ & $0.77(0.69,0.86)$ \\
\hline $50-64$ (Ref) & & 1.0 (ref) \\
\hline $65-74$ & $1.26(1.12,1.40)$ & $1.33(1.12,1.58)$ \\
\hline $75+$ & $0.65(0.57,0.74)$ & $0.96(0.77,1.19)$ \\
\hline \multicolumn{3}{|l|}{ Patient gender } \\
\hline Male (Ref) & 1.0 & 1.0 \\
\hline Female & $1.16(1.09,1.24)$ & $1.10(1.00,1.22)$ \\
\hline \multicolumn{3}{|l|}{ Ethnicity } \\
\hline $\begin{array}{l}\text { White, non-Latino } \\
\text { (Ref) }\end{array}$ & 1.0 & 1.0 \\
\hline Asian/API & $0.83(0.76,0.90)$ & $0.68(0.60,0.77)$ \\
\hline Black, non-Latino & $0.32(0.28,0.36)$ & $0.72(0.58,0.90)$ \\
\hline Latino/Hispanic & $0.52(0.46,0.59)$ & $0.84(0.79,1.03)$ \\
\hline Other race/ethnicity & $0.65(0.59,0.72)$ & $0.90(0.77,1.06)$ \\
\hline \multicolumn{3}{|l|}{ Primary language } \\
\hline English (Ref) & 1.0 & 1.0 \\
\hline $\begin{array}{l}\text { Non-English/unk/ } \\
\text { declined }\end{array}$ & $0.45(0.40,0.50)$ & $0.51(0.43,0.61)$ \\
\hline \multicolumn{3}{|l|}{ Insurance status } \\
\hline Commercial (Ref) & 1.0 & 1.0 \\
\hline Medicaid & $0.45(0.40,0.51)$ & $0.86(.70,1.06)$ \\
\hline Medicare & $0.52(0.47,0.58)$ & $0.91(.77,1.08)$ \\
\hline Medicare/Medicaid & $0.33(0.26,0.41)$ & $0.88(.58,1.34)$ \\
\hline Clinic visits & $1.10(1.08,1.11)$ & $1.17(1.14,1.20)$ \\
\hline \multicolumn{3}{|l|}{ Patient zip code } \\
\hline $\begin{array}{l}\text { San Francisco zip code } \\
\text { (Ref) }\end{array}$ & 1.0 & 1.0 \\
\hline $\begin{array}{l}\text { Non-San Francisco zip } \\
\text { code }\end{array}$ & $1.20(1.12,1.29)$ & $1.09(0.98,1.20)$ \\
\hline
\end{tabular}

patient-portal use. We speculate this occurs through (1) development of physician-patient trust relationship, and (2) physicians' own comfort with patient-portal use.
The differences seen between physician types may reflect long-term continuity and level of patient-physician trust that is less likely in shorter-term resident-patient relationships. While an early study raised concerns that dissatisfaction with one's PCP influenced increased patient-portal use, ${ }^{23}$ follow-up studies have since shown an association between increased use of a patient-portal and higher patient perceived trust in their physician, higher patient experience scores, and more patient loyalty. ${ }^{15,24}$ Another study found that patients with diabetes whose physicians scored better on quality measures had higher rates of portal use. ${ }^{25,}{ }^{26}$ Our results suggest a dose-response relationship between physician rank and portal use; physician rank may be a proxy for patient-physician relationship. It may be that interventions to enhance trust between patients and their resident PCPs may also enhance patient-portal use, with potential subsequent improvement in care quality and health. Alternatively, the fact that resident PCPs' patients had decreased odds of use may reflect physician inexperience and unfamiliarity with electronic patient communication. Our findings build on prior studies that show residents have more concerns with patients being able to view their clinical data ${ }^{27}$ and report less familiarity with electronic communication with patients compared to attendings. ${ }^{28}$ Conversely, increased PCP comfort with electronic communication may lead to increased patient use of patient-portals. In a cohort of diabetes patients in an integrated delivery system, there was an association between PCPs who had a high volume of secure messaging and patient use of secure messaging features of the patient-portal. ${ }^{29}$ Another study of patient-reported satisfaction with electronic health record (EHR) use during a clinic visit showed patients had higher overall satisfaction with attending physician use of the EHR compared to resident physician use. ${ }^{30}$ Efforts to increase patient use of portals may also need to keep in mind physician comfort with portal use.

Table 4 Multivariate Odds of Use and Active Use of the Patient-Portal Incorporating Physician Rank, Physician Gender, and Gender Concordance, Clustered by Physician

\begin{tabular}{|c|c|c|c|c|c|c|}
\hline \multirow[t]{3}{*}{ Characteristic } & \multicolumn{3}{|c|}{ All included patients } & \multicolumn{3}{|c|}{ Patient-portal users } \\
\hline & \multicolumn{3}{|c|}{$(N=17,699)$} & \multicolumn{3}{|l|}{$(N=9443)$} \\
\hline & $\begin{array}{l}\text { Non-use } \\
N=8256 \\
(\%)\end{array}$ & $\begin{array}{l}\text { Use } \\
N=9443 \\
(\%)\end{array}$ & AOR use $\dagger$ & $\begin{array}{l}\text { Passive use } \\
N=2406 \\
(\%)\end{array}$ & $\begin{array}{l}\text { Active use } \\
N=7037 \\
(\%)\end{array}$ & AOR use $\dagger$ \\
\hline \multicolumn{7}{|l|}{ Physician rank } \\
\hline Full professor (Ref) & 39.8 & $60.2^{*}$ & 1.0 & 22.4 & $77.6^{*}$ & 1.0 \\
\hline Associate professor & 41.7 & 58.3 & $\begin{array}{l}0.92(0.83- \\
1.02)\end{array}$ & 26.2 & 73.8 & $\begin{array}{l}0.81(0.70 \\
0.94)\end{array}$ \\
\hline Assistant professor/fellow & 46.5 & 53.5 & $\begin{array}{l}0.77(0.71- \\
0.84)\end{array}$ & 25.9 & 74.2 & $\begin{array}{l}0.90(0.80 \\
1.03)\end{array}$ \\
\hline Resident & 61.2 & 38.8 & $\begin{array}{l}0.49(0.45- \\
0.54)\end{array}$ & 31.9 & 68.1 & $\begin{array}{l}0.68(0.59 \\
0.78)\end{array}$ \\
\hline \multicolumn{7}{|l|}{ Physician gender } \\
\hline Male (Ref) & 46.2 & 53.9 & 1.0 & 25.3 & 74.7 & 1.0 \\
\hline Female & 47.1 & 52.9 & $\begin{array}{l}0.97(0.91- \\
1.04)\end{array}$ & 25.6 & 74.4 & $\begin{array}{l}1.03(0.92- \\
1.15)\end{array}$ \\
\hline $\begin{array}{l}\text { Gender concordance (patient and } \\
\text { physician) }\end{array}$ & 45.5 & $54.5^{*}$ & $\begin{array}{l}1.06(0.99- \\
1.13)\end{array}$ & 25.4 & 74.6 & $\begin{array}{l}1.02(0.92 \\
1.13)\end{array}$ \\
\hline
\end{tabular}

*Bivariate analyses $p<.05$

†Also adjusted for patient age, gender, racelethnicity, preferred language, insurance status, clinic visits, zip code 
Similarly deserving of future investigation is addressing potential resident concerns about competency handling portal messages and the need for attending backup for complex virtual patient encounters. Existing resident curricula on physician-patient communication have increased knowledge and appropriate behaviors and should integrate patient-portal use. ${ }^{28} \mathrm{~A}$ resident education curriculum targeting competency in patient-portal use showed promise in improving perceived care, comfort with secure messaging, and patient enrollment and engagement with the portal. ${ }^{18}$ Dissemination of curriculum may address perceived low self-efficacy and system barriers that contribute to residents being less likely to encourage their patients to use patient-portals.

An interesting finding in this study was that patients aged 65-74 were more likely to be users of patientportals, and among portal users, more likely to be active users compared to their younger counterparts. It is likely that younger patients are healthier and have less need to use the patient-portal compared to older patients. A survey of both young and older adults about preferences in use of electronic messaging to communicate with physicians found that older adults had similar enthusiasm for using electronic means to communicate with their care teams, ${ }^{31}$ and that for older patients $(>70)$, trust mediated this association. ${ }^{15}$ This may suggest that for older patients, trust developed between patients and physicians leads to using the patient-portal, and in turn, the complexity of their medical conditions leads to more active use. As this age group corresponds to the fastest growing demographic in the US healthcare system, it is an important target for increased outreach to encourage enrollment, as well as increased attention to minimize potential disparities for less advantaged older adults. In our study, $19 \%$ of patients were enrolled in the portal but did not use it; further investigation on why these patients did not use the portal could inform future initiatives. Sustained use of the patient-portal and use by particular vulnerable groups of patients may require additional efforts by health systems to provide technical support, and by physicians to enhance communication and rapport via portal use.

We found that each additional practice visit increased the odds of being a user of the patient-portal; and among users of the patient-portal, each additional practice visit increased the odds of active use of the portal. This may reflect increased patient engagement and physician-patient trust with each visit. Alternatively, it may reflect the heightened need for active PCP communication for patients with acute and active chronic illness. Our findings add to a mixed literature regarding the potential impact patient-portals have on in-person practice visits, with several studies showing an association between increased electronic messaging with a physician and decreases in office visits, $20,32,33$ but a subsequent study found the opposite association of increased access to online patient-portal associated with higher office visit utilization. ${ }^{34}$

\section{LIMITATIONS}

This study has several limitations. The study design is cross-sectional and we cannot infer causality. Our study population was limited to patients and physicians at one academic internal medicine practice and may not be generalizable to other practices that do not have an integrated structure. In addition, because we did not limit to patients with specific diagnoses, and the information we had about co-morbidities was incomplete, we did not control for patient co-morbidities, or severity of disease that may confound the association between physician type and use of the patient-portal. ${ }^{1}$ However, in our study setting, both attending physicians and resident physicians have medically complex patient panels. We did not have data on length of patient-physician relationship, which may also influence overall as well as active use of the patient-portal. Depending on their stage in training, resident physicians will have had the opportunity for continuity of some relationships of up to 3 years. The definitions we used for "use," "passive use," and "active use," while derived from prior literature, ${ }^{29}$ utilized counts of activity within a defined period and are subject to misclassification bias; if present though, this would bias the results toward the null hypothesis.

\section{CONCLUSION}

In conclusion, we found lower overall and active use of the patient-portal among patients with resident PCPs compared to patients with attending PCPs. As patient-portal adoption expands and the use of patient-portals for population health outreach initiatives (e.g., vaccinations, cancer screening) increases, there are potential unintended consequences of widening existing health disparities, particularly in settings in which trainees care for already vulnerable populations. Residency programs should adopt curricula to bolster trainee skills and competence in the use of the patient-portal for communication, while simultaneously examining ways in which to enhance patient comfort and trust communicating with their resident PCPs via the patient-portal.

Prior Presentations: Earlier version of this work was presented as a poster abstract at the 2016 Society of General Internal Medicine National Meeting, Hollywood, FL.

Corresponding Author: Brian Chan, MD MPH; Division of General Internal Medicine, Zuckerberg San Francisco General Hospital, University of California, San Francisco, CA, USA (e-mail: chanbri@ohsu.edu). 
Funders Brian Chan's effort was supported in part by the UCSF primary care research fellowship Ruth L. Kirschstein National Research Service Award (T32HP19025) and the AHRQ funded PCOR K12 award (K12HSO22981).

Courtney Lyles' effort was supported in part by the AHRQ career development award (ROOHSO22408).

\section{Compliance with Ethical Standards:}

The UCSF Institutional Review Board approved the research procedures.

Conflict of Interest: The authors declare that they do not have a conflict of interest.

\section{REFERENCES}

1. Ralston JD, Rutter CM, Carrell D, Hecht J, Rubanowice D, Simon GE Patient use of secure electronic messaging within a shared medical record: a cross-sectional study. J Gen Intern Med 2009;24:349-55.

2. EHR Incentive Program July 2016.2016. (Accessed 8/22/2016, 2016, at http://www.cms.gov/regulations-and-guidance/legislation/ehrincentiveprograms/dataandreports.html.)

3. Fraccaro $\mathbf{P}$, Vigo M, Balatsoukas $\mathbf{P}$, Buchan IE, Peek N, van der Veer SN. Patient portal adoption rates: a systematic literature review and meta-analysis. Stud Health Technol Inform 2017;245:79-83.

4. Haun JN, Patel NR, Lind JD, Antinori N. Large-scale survey findings inform patients' experiences in using secure messaging to engage in patient-provider communication and self-care management: a quantitative assessment. J Med Internet Res 2015;17:e282.

5. Goldzweig Dr CL, Orshansky Dr G, Paige Dr NM, et al. Electronic patient portals: Evidence on health outcomes, satisfaction, efficiency, and attitudes. Ann Intern Med 2013;159:677-87.

6. Zhou YY, Kanter MH, Wang JJ, Garrido T. Improved quality at Kaiser Permanente through e-mail between physicians and patients. Health Aff 2010;29: 1370-5.

7. Harris LT, Koepsell TD, Haneuse SJ, Martin DP, Ralston JD. Glycemic control associated with secure patient-provider messaging within a shared electronic medical record: a longitudinal analysis. Diabetes Care 2013;36:2726-33.

8. Lyles CR, Sarkar U, Schillinger D, et al. Refilling medications through an online patient portal: consistent improvements in adherence across racial/ethnic groups. J Am Med Inform Assoc 2016;23:e28-33.

9. Wright A, Poon EG, Wald J, et al. Randomized controlled trial of health maintenance reminders provided directly to patients through an electronic PHR. J Gen Intern Med 2012;27:85-92.

10. Griffin A, Skinner A, Thornhill J, Weinberger M. Patient portals: who uses them? what features do they use? and do they reduce hospital readmissions? Appl Clin Inform 2016;7:489-501.

11. Goel MS, Brown TL, Williams A, Hasnain-Wynia R, Thompson JA, Baker DW. Disparities in enrollment and use of an electronic patient portal. J Gen Intern Med 2011;26:1112-6.

12. Taha J, Czaja SJ, Sharit J, Morrow DG. Factors affecting usage of a personal health record (PHR) to manage health. Psychol Aging 2013;28:1124-39.

13. Gordon NP, Hornbrook MC. Differences in access to and preferences for using patient portals and other ehealth technologies based on race, ethnicity, and age: a database and survey study of seniors in a large health plan. J Med Internet Res 2016;18:e50.

14. Graetz I, Gordon N, Fung V, Hamity C, Reed ME. The digital divide and patient portals: internet access explained differences in patient portal use for secure messaging by age, race, and income. Med Care 2016;54:772-9.
15. Lyles CR, Sarkar U, Ralston JD, et al. Patient-provider communication and trust in relation to use of an online patient portal among diabetes patients: the Diabetes and Aging Study. J Am Med Inform Assoc 2013;20:1128-31.

16. Kittler AF, Carlson GL, Harris C, et al. Primary care physician attitudes towards using a secure web-based portal designed to facilitate electronic communication with patients. Inform Prim Care 2004;12:129-38.

17. Miller DP, Jr., Latulipe C, Melius KA, Quandt SA, Arcury TA. Primary care providers' views of patient portals: interview study of perceived benefits and consequences. J Med Internet Res 2016;18:e8.

18. Crotty BH, Mostaghimi A, Landon BE. Preparing residents for future practice: report of a curriculum for electronic patient-doctor communication. Postgrad Med J 2013;89:554-9.

19. Liederman EM, Lee JC, Baquero VH, Seites PG. Patient-physician web messaging. The impact on message volume and satisfaction. J Gen Intern Med 2005;20:52-7.

20. Weingart SN, Rind $\mathbf{D}$, Tofias $\mathbf{Z}$, Sands $\mathbf{D Z}$. Who uses the patient internet portal? The patientsite experience. J Am Med Inform Assoc 2006;13:91-

21. Goel MS, Brown TL, Williams A, Cooper AJ, Hasnain-Wynia R, Baker DW. Patient reported barriers to enrolling in a patient portal. J Am Med Inform Assoc 2011;18 Suppl 1:i8-12.

22. Lyles CR, Allen JY, Poole D, Tieu L, Kanter MH, Garrido T. "I Want to Keep the Personal Relationship With My Doctor": understanding barriers to portal use among African Americans and Latinos. J Med Internet Res 2016;18:e263.

23. Zickmund SL, Hess $\mathbf{R}$, Bryce $\mathbf{C L}$, et al. Interest in the use of computerized patient portals: role of the provider-patient relationship. $\mathrm{J}$ Gen Intern Med 2008;23:20-6.

24. Turley M, Garrido T, Lowenthal A, Zhou YY. Association between personal health record enrollment and patient loyalty. Am J Manag Care 2012;18:e248-53.

25. Tenforde M, Nowacki A, Jain A, Hickner J. The association between personal health record use and diabetes quality measures. J Gen Intern Med 2012;27:420-4.

26. Bredfeldt CE, Compton-Phillips AL, Snyder MH. Effects of between visit physician-patient communication on Diabetes Recognition Program scores. Int J Qual Health Care 2011;23:664-73.

27. Keplinger LE, Koopman RJ, Mehr DR, et al. Patient portal implementation: resident and attending physician attitudes. Fam Med 2013;45:335-40.

28. Paladine HL, Miller K, White B, Feifer C. Study of a novel curriculum on electronic communication in family medicine residencies. Fam Med 2010;42:314-21.

29. Weppner WG, Ralston JD, Koepsell TD, et al. Use of a shared medical record with secure messaging by older patients with diabetes. Diabetes Care 2010;33:2314-9.

30. Lee WW, Alkureishi MA, Ukabiala O, et al. Patient perceptions of electronic medical record use by faculty and resident physicians: a Mixed Methods Study. J Gen Intern Med 2016;31:1315-22.

31. Lam R, Lin VS, Senelick WS, Tran HP, Moore AA, Koretz B. Older adult consumers' attitudes and preferences on electronic patient-physician messaging. Am J Manag Care 2013;19:eSP7-11.

32. Zhou YY, Garrido T, Chin HL, Wiesenthal AM, Liang LL. Patient access to an electronic health record with secure messaging: impact on primary care utilization. Am J Manag Care 2007;13:418-24.

33. Chen C, Garrido T, Chock D, Okawa G, Liang L. The Kaiser Permanente Electronic Health Record: transforming and streamlining modalities of care. Health Aff 2009;28:323-33.

34. Palen TE, Ross C, Powers JD, Xu S. Association of online patient access to clinicians and medical records with use of clinical services. JAMA 2012;308:2012-9. 